\title{
The Relationship between Intellectual Property Risk and Stability of Asymmetric Research and Development Alliance
}

\author{
Jie Zhen $\mathbb{D}^{1},{ }^{1}$ Zhuopin Guo $\mathbb{D}^{2},{ }^{2}$ Yiying Qu $\mathbb{D},{ }^{1}$ and Hao Ren ${ }^{2}$ \\ ${ }^{1}$ Business School, East China University of Political Science and Law, Shanghai, China \\ ${ }^{2}$ School of Economics and Management, Tongji University, Shanghai, China \\ Correspondence should be addressed to Zhuopin Guo; guozhuopin@126.com and Yiying Qu; quyiyinghz@126.com
}

Received 25 April 2021; Revised 26 July 2021; Accepted 21 August 2021; Published 6 September 2021

Academic Editor: Yi Su

Copyright $(02021$ Jie Zhen et al. This is an open access article distributed under the Creative Commons Attribution License, which permits unrestricted use, distribution, and reproduction in any medium, provided the original work is properly cited.

Small- and medium-sized enterprises (SMEs) establish asymmetric research and development (R\&D) alliance with core enterprises to improve innovation efficiency. Unfortunately, the gap in the status and bargaining power between enterprises in such partnerships makes the intellectual property risk situation complicated. While gaining support and assistance from core enterprises, SMEs face the risk of exposing their core knowledge and key resources, which seriously affects the stability of R\&D alliance and the sustainability of cooperative innovation. How to protect the intellectual property rights of SMEs in the asymmetric R\&D alliance and improve the alliance's stability is an urgent problem to be solved. Based on the theory of resource dependence and transaction cost, this study uses 260 high-tech companies participating in the asymmetric R\&D alliance as a sample to conduct empirical research from the perspective of SMEs in a weak position. The purpose of this study is to sort out the types of intellectual property risks in the alliance and clarify the relationship between them and the stability of asymmetric R\&D alliance. Furthermore, this study examines the moderating effects of contract governance mechanisms and relational contracts to explore effective governance mechanisms at the alliance level. Empirical results show that the intellectual property investment risk and the intellectual property loss risk have a significant negative impact on the stability of asymmetric R\&D alliance. The contract governance mechanism negatively moderates the impact of intellectual property investment risk on the stability of the asymmetric R\&D alliance. The relationship governance mechanism negatively moderates the impact of intellectual property loss risk on the stability of the asymmetric R\&D alliance. The contract and relationship governance mechanism jointly negatively moderate the impact of intellectual property investment risk and loss risk on the stability of the asymmetric R\&D alliance.

\section{Introduction}

Small- and medium-sized enterprises (SMEs) are more likely to encounter issues regarding limited innovation resources than core enterprises. When facing market pressure, they will seek to establish research and development (R\&D) partnerships with core enterprises in the industry to obtain complementary innovation resources. In this cooperative relationship, SMEs are relatively dependent on the resources of the core enterprise, leading to the unequal status of the two parties in the cooperative relationship, thus forming an asymmetric R\&D alliance [1]. Although the asymmetric R\&D alliance can bring substantial potential benefits to both partners, the failure rate of this alliance form is over $60 \%$, and the asymmetric $\mathrm{R} \& \mathrm{D}$ alliance is precarious $[2,3]$. However, scholarly attention has not yet turned to the field of asymmetric alliance but has focused on symmetric alliance $[4,5]$. Some scholars are aware of the universality and importance of asymmetric alliance but still pay more attention to dominant core enterprises $[6,7]$. In fact, in asymmetric alliance, SMEs face the risk of exposing their core knowledge and key resources while obtaining the support and help from core enterprises [8], that is, facing the 'border confusion'. If SMEs can effectively and appropriately protect their key resources from infringement, they can obtain new technological achievements and competitive advantages through cooperative R\&D with core enterprises; otherwise, they will lose core knowledge and existing benefits.

Furthermore, given the lower bargaining power of SMEs in asymmetric alliance, core enterprises can use their 
dominant position to exercise opportunistic behavior to make profits. Therefore, in the asymmetric R\&D alliance, SMEs face greater intellectual property risks [9]. This longterm asymmetric dependency relationship leads to unequal risk and inconsistent benefit distribution among R\&D alliance members, thus exacerbating conflicts among members and leading to the breakdown of alliance relationships [10]. Therefore, a huge challenge is knowing how weak enterprises can obtain actual and long-term benefits in asymmetric $\mathrm{R} \& \mathrm{D}$ partnerships while protecting their key knowledge and interests from illegal encroachment by strong enterprises and maintaining the stability of asymmetric R\&D alliance. Constructing an effective alliance governance mechanism at the alliance level is necessary to protect the core intellectual property rights of the alliance members, especially the disadvantaged enterprises, and reduce their intellectual property risks. Doing so encourages alliance members, especially SMEs, to contribute new knowledge, improves cooperative innovation performance, and ultimately advances the stability of asymmetric R\&D alliance.

The governance mechanism in the alliance mainly includes contract governance and relationship governance [11]. From the perspective of the governance mechanism, the contract is the most effective means to prevent leakage of intellectual property [12]. As a necessary condition for reducing the risk of knowledge leakage, contracts can effectively improve alliance performance [13]. Furthermore, relevant empirical studies have shown that trust can effectively reduce the risk of knowledge loss, thereby reducing knowledge protection behavior in innovation alliance [14]. Trust among alliance members can effectively avoid opportunistic behaviors and positively impact the cooperation of technology alliance [15]. The cooperative innovation in $\mathrm{R} \& \mathrm{D}$ alliance, especially in asymmetric $\mathrm{R} \& \mathrm{D}$ alliance, is a complex and dynamic process, the complexity of knowledge itself, the nonequivalence of resource dependence among alliance members, and the differences in the willingness of alliance members to share, resulting in the governance of asymmetric $\mathrm{R} \& \mathrm{D}$ alliance intellectual property risk that must consider contract governance and relationship governance to promote its stability.

In conclusion, the stability of an asymmetric R\&D alliance has become an urgent problem to address. Still, few studies on such partnerships can be found, especially from the perspective of SMEs in a weak position. Furthermore, in terms of the governance mechanism of R\&D alliance stability, most of the existing studies are from the dimensions of single contract governance or relationship governance. Few studies unify the two types of governance mechanisms in an integrated framework. The improvement of the stability of R\&D alliance requires the promotion of knowledge transfer between enterprises by inhibiting the degree to which cooperative enterprises protect their knowledge. This promotion is manifested in the joint regulating effect of contract governance and relationship governance. Therefore, the overall consideration of the two types of governance mechanisms and the analysis of their governance effects on the relationship between intellectual property risk and asymmetric R\&D alliance stability will provide more guidance for enhancing the stability of such alliance. This study explores the factors affecting the stability of asymmetric $R \& D$ alliance from the perspective of intellectual property and effective governance mechanisms at the alliance level to provide adequate guidance for the theoretical and practical development of asymmetric $\mathrm{R} \& \mathrm{D}$ alliance. Thus, this study investigates 260 high-tech companies participating in asymmetric R\&D alliance and discusses the stability of asymmetric R\&D alliance from the perspective of intellectual property risk. This study also introduces contract governance mechanisms and relationship governance mechanisms as moderation variables to analyze the individual governance mechanism and joint governance mechanism on the impact of intellectual property risk on the stability of asymmetric R\&D alliance.

\section{Theoretical Basis}

2.1. Asymmetric R\&D Alliance Stability. Resource dependence theory holds that, depending on the importance, competitiveness, and scarcity of resources, differences are observed in the degree of dependence among enterprises in the alliance [16]. In some $R \& D$ alliances, the degree of dependence of members on each other's resources varies, resulting in a considerable disparity in the status of members within the alliance. This article defines this type of alliance as an asymmetric R\&D alliance. The resource-based theory believes that seeking the support of key resources, such as technology or capital, is the main purpose of enterprises joining the R\&D alliance. Therefore, the key factor in forming an asymmetric R\&D alliance lies in acquiring and integrating scarce resources between SMEs and core enterprises [17].

Asymmetric R\&D alliance stability means that, in the process of achieving the goals of an R\&D alliance, SMEs and core enterprises steadily implement R\&D alliance strategies following established plans, contracts, and goals. It is a relative and dynamic equilibrium that can ensure the normal fluctuations of the R\&D alliance relationship. The stability of the asymmetric $R \& D$ alliance is manifested in the state, where no member of the asymmetric $R \& D$ alliance wants to break away from the alliance relationship and ensure the usual maintenance and development of the R\&D alliance system [18].

2.2. Intellectual Property Risk. In cooperative innovation, knowledge sharing among partners will cause the enterprise's knowledge resources to face a series of risks brought by the opportunistic behavior of partners. One of the primary purposes of enterprises joining $\mathrm{R} \& \mathrm{D}$ alliance is to obtain scarce external knowledge through communication and sharing with alliance members. However, given the intangibility of knowledge and the concealment of loss, enterprises are vulnerable to partner opportunism in the process of participating in $\mathrm{R} \& \mathrm{D}$ cooperation. In cooperative $\mathrm{R} \& \mathrm{D}$, intellectual property risks are events and their possibilities triggered by the opportunistic behavior of each 
subject that negatively impact the current or potential rights and interests of intellectual property holders [19]. Intellectual property risk is divided into two categories. One is the risk of intellectual property investment; that is, other partners fail to invest the information and knowledge they promised following the provisions of the cooperation contract, resulting in the risk that the alliance and the enterprise themselves cannot obtain their due rights and interests. The second is the intellectual property loss risk, mainly because of the exposure of key knowledge in the process of cooperation, resulting in the risk of forced occupation or illegal misappropriation of intellectual resources by alliance partners [20].

2.3. Governance Mechanism. Two important governance methods in $\mathrm{R} \& \mathrm{D}$ alliance are contract governance and relationship governance, which emphasize reducing opportunistic behavior and transaction risks in the alliance. Contract governance is to stipulate the rights and obligations of all parties by signing detailed formal contracts with alliance members and as the basis for subsequent dispute settlement [11]. Transaction cost theory believes that the contract has a control function by enhancing the completeness of the contract to increase the trust level of both parties, thereby reducing the opportunistic behavior of alliance members and reducing transaction costs [21]. Furthermore, the relationship governance in the alliance is based on trust, embeds the transaction relationship in the complex social background, and emphasizes establishing emotional connections between members [22]. Unlike transaction cost theory, social exchange theory believes that the relationship established by alliance partners in long-term communication is helpful in the mutual recognition and understanding of the partners and actively controls their opportunistic behavior through social rules and self-restraint [23].

\section{Hypotheses Development}

3.1. Intellectual Property Risk and Stability of Asymmetric $R \& D$ Alliance. In the asymmetric R\&D alliance, SMEs have relatively low status and bargaining power because of their strong dependence on core enterprises in technology, capital and market channels [1]. This kind of power imbalance can easily lead to the core enterprises using their dominant position to make profits and affect the stability of asymmetric $\mathrm{R} \& \mathrm{D}$ alliance. The contradiction between the exclusiveness of intellectual property rights and the requirements for intellectual property sharing in cooperative innovation activities in the $\mathrm{R} \& \mathrm{D}$ alliance determines the conflict of intellectual property interests among alliance members. Facing the high risk of intellectual property investment, disadvantaged SMEs will also take preventive measures, including concealing fundamental knowledge or reducing their investment in key knowledge and skills, to avoid high intellectual property investment risk [24]. The $\mathrm{R} \& \mathrm{D}$ alliance is based on the system's openness through the agglomeration of innovative resources to achieve cooperative innovation. The inventory and sharing level of the alliance resource pool directly affects the stability and operational efficiency of the alliance. The opportunistic behavior of members leads to insufficient investment in effective knowledge resources in the alliance resource pool, which damages the cooperative innovation performance of the $R \& D$ alliance and the stability of the $R \& D$ alliance. Thus, we put forward the following hypothesis:

$\mathrm{H1}$ : The intellectual property investment risk negatively affects the stability of an asymmetric R\&D alliance.

Given the characteristics of intangibility and specificity of intellectual property, once an intellectual property holding company invests its knowledge in the R\&D alliance, it will weaken its ability to control it and cause the risk of leakage or even infringement of intellectual property rights [25]. This risk is likely to occur in asymmetric $\mathrm{R} \& \mathrm{D}$ alliance. When facing a high risk of intellectual property loss, SMEs will take corresponding measures to prevent the leakage of core knowledge to safeguard personal interests [26]. When the collective interests of the R\&D alliance conflict with their personal interests, the enterprise, as an independent economic entity, often chooses to sacrifice the overall interest of the alliance to maximize its interests [27]. Therefore, in the asymmetric R\&D alliance, given the existence of expected intellectual property loss risks, such as malicious theft or accidental disclosure of intellectual property rights by strong partners in the process of $\mathrm{R} \& \mathrm{D}$ cooperation, the willingness and level of SMEs to share intellectual property rights are reduced, which is not conducive to alliance members in the absorption and integration of knowledge, reducing the learning efficiency between organizations and affecting the stability of asymmetric R\&D alliance. Thus, we put forward the following hypothesis:

$\mathrm{H} 2$ : The intellectual property loss risk negatively affects the stability of an asymmetric $\mathrm{R} \& \mathrm{D}$ alliance.

\subsection{Moderating Role of Individual Governance Mechanism}

3.2.1. Moderating Role of Contract Governance. The theory of institutional economics points out that, in the R\&D alliance, regulating and guiding the behavior of the subject to suppress opportunistic behavior are necessary. The negative effects of subjective behavior caused by opportunistic tendencies make the R\&D alliance inefficient or even disintegrate. Therefore, how to suppress the opportunistic behavior of alliance members has become the focus of R\&D alliance governance. Transaction cost theory believes that formal governance structures and contracts can effectively suppress opportunistic tendencies [28]. Contractual governance emphasizes the detailed provisions of the rights and obligations of R\&D alliance members by signing legally effective clauses [29] and relying on the binding force of law to ensure that alliance members fulfil their commitments [30].

Based on the process perspective, contract formulation is a process of the alliance members' game and of coordinating 
the expected benefits of the parties [31]. Contract governance coordinates the individual interests of the alliance members and the common interests of the alliance by jointly agreeing on the scope and extent of intellectual property sharing among asymmetric R\&D alliance members and the distribution mechanism of cooperative $R \& D$ results [32]. It also allows alliance members to acquire knowledge and enhance their expertise legally, reducing the expectations of asymmetric R\&D alliance members, especially disadvantaged SMEs, about intellectual property risks, encouraging them to contribute new knowledge, expanding the public knowledge set of asymmetric R\&D alliance, improving the consistency of objectives of alliance members and maintaining stable R\&D partnerships.

Based on the perspective of results, the establishment of contractual relationships can effectively reduce mutual distrust, especially when the relationship between the two parties is not close, or the rights of both parties are not equal. A formal governance system will make alliance members feel that they have enough control over partner behavior. Thus, their confidence is enhanced, especially vulnerable members', in cooperative behavior, and the investment of exclusive resources is increased, such as intellectual property [33], which is conducive to enriching the alliance resource pool and improving the stability of asymmetric R\&D alliance.

Therefore, in the governance of the relationship between intellectual property risk and asymmetric $R \& D$ alliance stability, contract governance mainly reduces intellectual property risks by reducing the differences between alliance members and controlling the possibility of knowledge spill over. The higher the degree of contract governance is, the more the $\mathrm{R} \& \mathrm{D}$ alliance can control intellectual transaction activities, reduce intellectual property risks caused by incomplete sharing or exceeding the permitted use of intellectual property, and restrain the negative effects of intellectual property risks on the stability of asymmetric R\&D alliance influences. Thus, the following hypotheses are proposed:

H3: The contract governance mechanism can effectively moderate the relationship between intellectual property investment risk and the stability of the asymmetric $\mathrm{R} \& \mathrm{D}$ alliance. That is, the higher the degree of contract governance, the weaker the impact of intellectual property investment risk on the stability of the asymmetric R\&D alliance.

H4: The contract governance mechanism can effectively regulate the relationship between intellectual property loss risk and the stability of asymmetric R\&D alliance. That is, the higher the degree of contract governance is, the weaker the intellectual property loss risk will affect the stability of the asymmetric R\&D alliance.

3.2.2. Moderating Role of Relationship Governance. Social exchange theory believes that the sharing of intellectual property rights between alliance partners is a repetitive exchange embedded in the social network [34]. The relationship contract governance mechanism emphasizes that enterprises rely on social norms and values for self-discipline and strengthen the emotional connection between alliance partners and establish mutual trust relationships, thereby reducing transaction costs under uncertain conditions and strengthening the willingness and continuity of $\mathrm{R} \& \mathrm{D}$ alliance members to cooperate on intellectual property [35].

As far as the alliance level is concerned, establishing a relationship is also a process of enhancing trust among alliance subjects. Firstly, the relationship governance based on social norms can promote enterprises to restrain their opportunistic behavior tendency actively and enhance their confidence in other R\&D alliance partners. Partners will pay attention to their reputation and will not use their superior position in the alliance to abuse or steal the core knowledge resources of the enterprise deliberately. Thus, the concerns of alliance members will lessen, especially SMEs with lower status in the alliance, about the security of their intellectual property. Consequently, SEMs are encouraged to share their intellectual property, improve the efficiency of interaction [36], and enhance the stability of asymmetric R\&D alliance. Secondly, the enterprise that adopts relationship governance helps gain the trust and recognition of other members from the perceptual level [37]. Through relational contract governance, the views and understandings of partners on issues are more consistent, thus improving the reputation and legitimacy of the enterprise within the alliance and obtaining more shared resources [38]. The establishment of a good partnership can stimulate the positive behavior motivation of R\&D alliance members and lays the foundation for the smooth development of R\&D cooperation among alliance members and the alliance's stability. Therefore, the relationship governance mechanism positively affects the operation of asymmetric $\mathrm{R} \& \mathrm{D}$ alliance through the positive reinforcement of the alliance subject relationship while negatively reinforcing the negative behavior of the alliance subject. Therefore, this article believes that the relationship governance mechanisms, such as trust and reputation, can effectively reduce intellectual property risks and maintain the stability of asymmetric R\&D alliance. Thus, the following hypotheses are proposed:

H5: The relationship governance mechanism can effectively moderate the relationship between the intellectual property investment risk and the stability of asymmetric $\mathrm{R} \& \mathrm{D}$ alliance. That is, the higher the degree of relationship governance, the weaker the impact of intellectual property investment risk on the stability of asymmetric R\&D alliance.

H6: The relationship governance mechanism can effectively moderate the relationship between the intellectual property loss risk and the stability of asymmetric $\mathrm{R} \& \mathrm{D}$ alliance. That is, the higher the degree of relationship governance is, the weaker the intellectual property loss risk will affect the stability of the asymmetric R\&D alliance.

3.3. Joint Moderating Role of Contract Governance and Relationship Governance Mechanism. Although the contract governance mechanism and the relationship governance 
mechanism can effectively restrain the behavior of alliance members, they have great differences in their action mechanism. The contract governance mechanism assumes that alliance members tend to be egoistic and need to restrict their behavior through negative incentives, such as punishment. In contrast, the relationship governance mechanism emphasizes establishing trust among the members and actively restrains members opportunism tendency by relying on values and social norms. In other words, the contract governance mechanism achieves the purpose of restraining the behavior of alliance members by controlling their negative extrinsic motivation, whereas the relationship governance mechanism constrains their behavior by stimulating the positive intrinsic motivation of alliance members [39]. Thus, does the joint use of the contract and relationship governance mechanism have better results?

On the one hand, the relationship contract governance is helpful in making up for the deficiency of contract governance. Firstly, the completeness of contracts is often accompanied by rigidity and inflexibility. Under the complete contract governance mechanism, members of the asymmetric R\&D alliance will only share the intellectual property content specified in the contract and strictly monitor the exchange and use of intellectual property throughout the process. Doing so stimulates mutual prevention and vigilance among alliance members easily [40], hinders the sharing of knowledge resources among alliance members, and leads to asymmetric R\&D alliance breakdown. The establishment of a relationship governance mechanism means two things. The members of the asymmetric R\&D alliance believe that their partners will not maliciously steal and disclose their key intellectual property. The trusted members will also actively suppress their opportunistic tendencies [41], avoid the prisoner's dilemma of a single transaction, reduce the cost of contract signing and supervision, and facilitate repeated transactions. These will effectively curb intellectual property risks and enhance the willingness to share intellectual property among alliance members. Making up for the deficiency of contract governance mechanism on controlling the intellectual property risk to a certain extent and maintaining a good interaction between alliance members are helpful. Secondly, the completeness of the contract governance mechanism needs to be supplemented by the relationship governance mechanism. When the level of trust among members of an asymmetric $\mathrm{R} \& \mathrm{D}$ alliance is low, the level of intellectual property cooperation among members is also relatively low. At this time, only rough and straightforward contract terms can meet the needs. With the gradual deepening of trust between the two parties in the asymmetric R\&D alliance, the breadth and depth of R\&D cooperation between alliance members have also been expanding, which requires more comprehensive, complex, and detailed contractual terms to adapt to it. Meanwhile, the tacit behavioral understanding and cognitive experience formed by alliance partners in the long-term mutual communication will continue to deepen and will be gradually fixed in the form of formal contracts, forming a supplement and improvement to the original contract content [42]. Consequently, the intellectual property risks caused by members' opportunistic behavior will be restrained, making the asymmetric R\&D alliance more stable and smoother.

On the other hand, relationship governance also requires contract governance to coordinate. Firstly, the establishment and deepening of the relationship require the contract to provide a formal communication channel and platform [43]. In the initial stage of establishing the R\&D alliance, especially asymmetric R\&D alliance, the trust among alliance members is low. If no contract governance mechanism is involved, vulnerable members will reject deep intellectual property sharing, because of the lack of formal communication platforms and the expectation of high intellectual property investment and loss risk. Thus, the efficiency of $\mathrm{R} \& \mathrm{D}$ cooperation will be hindered, and the stability of asymmetric R\&D alliance will be affected. At this time, a complete contractual governance mechanism can use the authority of law to encourage members of the asymmetric $\mathrm{R} \& \mathrm{D}$ alliance to build formal knowledge sharing channels, deepen mutual understanding through formal communication, gradually reach consensus on issues and basic trust, and further develop formal communication into relationship-based informal communication, continuously strengthening the relationship between members [22] and reducing the intellectual property risk concerns of alliance members, especially vulnerable companies.

Secondly, the governance of in-depth relationship contracts requires the protection of contracts. Although the establishment of relationship contracts, such as trust, helps members of asymmetric $\mathrm{R} \& \mathrm{D}$ alliance strengthen the openness of intellectual property and other knowledge resources and deepen interorganizational learning, excessive trust will weaken supervision [44], leading to alliance members. In particular, disadvantaged SMEs face higher investment in intellectual property rights and risk of loss. Contracts based on the legal system can protect the interests of underprivileged companies that contribute intellectual property rights through the authority of the law [34]. Thus, it makes up for the potential intellectual property risks caused by the excessive trust and provides a formal guarantee for the governance of relationship contracts. Furthermore, the relationship governance mechanism and the contract governance mechanism can jointly influence the relationship between intellectual property risk and asymmetric $\mathrm{R} \& \mathrm{D}$ alliance stability. The combined use of contract governance and relationship governance mechanism emphasizes the role of relationship governance in asymmetric $\mathrm{R} \& \mathrm{D}$ alliance to avoid intellectual property risk and strengthen trust. It also attaches importance to the contract governance in the guarantee of R\&D cooperation innovation performance and the containment of opportunism in asymmetric R\&D alliance. Therefore, when high-strength contract governance and high-strength relationship governance are adopted, the negative impact of intellectual property risk on the stability of asymmetric R\&D alliance will be relatively weakened. Therefore, this study proposes the following assumptions:

H7: Contracts and relationship governance have a joint moderating effect on the relationship between intellectual property investment risk and asymmetric $R \& D$ 
alliance stability. That is, when the "double highstrength" governance combination is implemented, the intellectual property investment risk has the weakest impact on asymmetric R\&D alliance stability.

H8: Contracts and relationship governance have a joint regulation effect on the relationship between intellectual property loss risk and asymmetric R\&D alliance stability. That is, when the "double high-strength" governance combination is implemented, the intellectual property loss risk has the weakest impact on asymmetric R\&D alliance stability.

In summary, this paper constructs the model of the mechanism of the intellectual property risks on the stability of asymmetric R\&D alliance, as shown in Figure 1.

\section{Research Design}

4.1. Data and Samples. This study uses questionnaire surveys to obtain the data needed for the research. It conducts a sample survey of technology-based enterprises in strategic emerging industrial clusters, such as new energy, new materials, biomedicine, and software in Shanghai, Zhejiang, and Shandong provinces. The reasons are as follows. Firstly, scientific and technological enterprises have relatively frequent cooperative $\mathrm{R} \& \mathrm{D}$ activities, and intellectual property is the source of the core competitiveness of scientific and technological enterprises. Thus, this type of enterprise tends to have a stronger awareness of intellectual property protection. Secondly, the strategic emerging industry cluster comprises leading enterprises and SMEs that provide industrial supporting services a typical asymmetric cooperative relationship. The research team randomly distributed questionnaires to executive teams or $\mathrm{R} \& \mathrm{D}$ managers of technology-based companies in the cluster from June to October 2019. As the company's management group, corporate executives can participate in the decision-making of asymmetric $\mathrm{R} \& \mathrm{D}$ alliance, and $\mathrm{R} \& \mathrm{D}$ managers directly participate in R\&D cooperation activities within the alliance. These two groups of people have a deeper understanding of the $R \& D$ cooperation relationship in the alliance and provide high-quality data. A total of 600 questionnaires were distributed in the survey, and 260 valid questionnaires were obtained after deleting incomplete and invalid questionnaires with apparent regular responses. The effective response rate was $43.33 \%$.

4.2. Variable Measurement. The intellectual property risk scale refers to the research results of Heiman and Nickerson (2004) [45]. The contract governance mechanism is based on Nambisan and Sawhney (2011) [46]. The measurement of relationship governance mechanism refers to Marcus (2005) [47]. The stability of R\&D alliance refers to Jiang and Gao (2008) [48] to measure the stability of R\&D alliance from the three dimensions: alliance relationship satisfaction, alliance performance level, and desire to continue the alliance.

The above scales all use the seven-point Likert scale, where 1 means "completely nonconforming" and 7 means "completely conforming." This study selects the company's age and size as the control variables of the model. The size of the enterprise is expressed by the logarithm of the total number of employees. Its natural logarithm measures the length of the enterprise.

\section{Data Analysis}

5.1. Reliability and Validity Test. This study used SPSS 20.0 software to test the internal consistency of the data and utilizes the Alpha model to test Cronbach's $\alpha$ coefficient. As shown in Table 1, Cronbach's $\alpha$ coefficient of all scales is between 0.847 and 0.909 . The scale used in this study has good reliability. Table 1 shows that all factor loads are above 0.7 , the combined reliability is above 0.8 , and the average extracted variance value (AVE) is above 0.5. Therefore, all prove that the scale has sufficient aggregate validity.

This study conducts confirmatory factor analysis through AMOS22.0. As shown in Table 2, compared with other models, the five-factor model has a better fit $(\chi 2 / \mathrm{df}=3.467, \mathrm{CFI}=0.897$, $\mathrm{GFI}=0.851, \mathrm{NFI}=0.907, \mathrm{RMSEA}=0.078)$, and all meet the statistical standards. Namely, the ratio of chi-square degrees of freedom is below 5.0; CFI, NFI, and GFI are all above 0.8; and RMSEA is below 0.08 .

Table 3 shows the results of the correlation analysis. The square root of the AVE value is much larger than the values in the rows and columns, which indicates that all the variables used in this study have good discrimination validity.

5.2. Hypothetical Test. This study draws on the method of Hair et al. (1998) [49], the hierarchical regression method to test the moderate effect. After centralization, the main effect is used for regression to eliminate the multicollinearity between the main effect and the interaction term. This study also performs a simple slope analysis and draws a slope diagram accordingly [50].

Table 4 shows that the intellectual property investment risk has a significant negative impact on the asymmetric R\&D alliance stability $(\beta=-0.317, P<0.01)$. Thus, $\mathrm{H} 1$ is verified. The intellectual property loss risk significantly negatively affects the asymmetric $\mathrm{R} \& \mathrm{D}$ alliance stability $(\beta=-0.330, P<0.01)$. Thus, $\mathrm{H} 2$ is confirmed. Contract governance has a positive impact on asymmetric $\mathrm{R} \& \mathrm{D}$ alliance stability $(\beta=0.151, P<0.01)$, and the relationship governance positively affects asymmetric R\&D alliance stability $(\beta=0.374, P<0.001)$. Contract governance has a significant negative moderating effect on the relationship between intellectual property investment risk and asymmetric R\&D alliance stability $(\beta=-0.230, P<0.01)$. Thus, $\mathrm{H} 3$ is verified. The contract governance has no significant moderating effect on the relationship between intellectual property loss risk and asymmetric R\&D alliance stability $(P<0.05)$. Thus, $\mathrm{H} 4$ is rejected. The relationship governance has no significant moderating effect on the relationship between intellectual property investment risk and asymmetric R\&D alliance stability $(P>0.05)$. Thus, $\mathrm{H} 5$ is rejected. The relationship governance has a significant negative moderating effect on the relationship between intellectual property loss risk and asymmetric R\&D alliance stability 


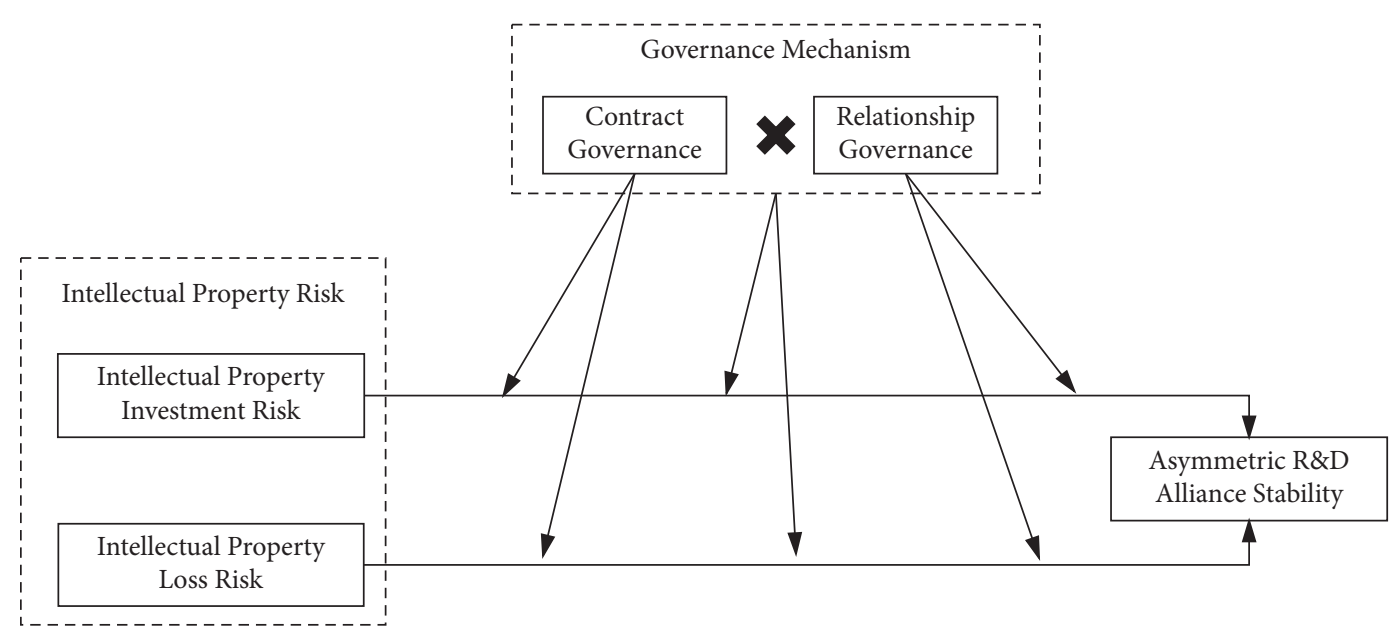

FIgURE 1: Conceptual framework.

TABLE 1: Table of reliability and validity analysis.

\begin{tabular}{|c|c|c|c|c|c|c|}
\hline Variable & Dimension & Mean & Std & Cronbach's $\alpha$ & $\mathrm{Cr}$ & AVE \\
\hline \multirow{6}{*}{ Asymmetric R\&D alliance stability (AS) } & AS1 & 4.4652 & 0.763 & \multirow{6}{*}{0.909} & \multirow{6}{*}{0.915} & \multirow{6}{*}{0.711} \\
\hline & AS2 & 4.6000 & 0.752 & & & \\
\hline & AS3 & 4.3101 & 0.847 & & & \\
\hline & AS4 & 4.3954 & 0.891 & & & \\
\hline & AS5 & 4.4574 & 0.752 & & & \\
\hline & AS6 & 4.4962 & 0.796 & & & \\
\hline \multirow{4}{*}{ Intellectual property loss risk (LS) } & LS1 & 3.7154 & 0.589 & \multirow{4}{*}{0.847} & \multirow{4}{*}{0.883} & \multirow{4}{*}{0.596} \\
\hline & LS2 & 4.0769 & 0.842 & & & \\
\hline & LS3 & 4.1692 & 0.832 & & & \\
\hline & LS4 & 4.0923 & 0.662 & & & \\
\hline \multirow{3}{*}{ Intellectual property investment risk (IS) } & IS1 & 3.5923 & 0.769 & \multirow{3}{*}{0.907} & \multirow{3}{*}{0.895} & \multirow{3}{*}{0.697} \\
\hline & IS2 & 3.4077 & 0.851 & & & \\
\hline & IS3 & 3.2462 & 0.741 & & & \\
\hline \multirow{3}{*}{ Relationship governance (RG) } & RG1 & 5.3488 & 0.561 & \multirow{3}{*}{0.890} & \multirow{3}{*}{0.904} & \multirow{3}{*}{0.601} \\
\hline & RG2 & 4.6667 & 0.534 & & & \\
\hline & RG3 & 5.0078 & 1.071 & & & \\
\hline \multirow{3}{*}{ Contract governance (CG) } & CG1 & 4.8372 & 0.726 & \multirow{3}{*}{0.811} & \multirow{3}{*}{0.900} & \multirow{3}{*}{.653} \\
\hline & CG2 & 4.9692 & 0.939 & & & \\
\hline & CG3 & 4.9147 & 0.837 & & & \\
\hline
\end{tabular}

TABle 2: Comparison of models.

\begin{tabular}{lccccrr}
\hline Model & Description & $X^{2} / \mathrm{df}$ & CFI & NFI & GFI & RMSEA \\
\hline Basic model & Five-factor model & 3.467 & 0.897 & 0.907 & 0.851 & 0.078 \\
Model 1 & Four factor model & 4.043 & 0.857 & 0.820 & 0.821 \\
Model 2 & Three factor model & 4.341 & 0.842 & 0.806 & 0.809 & 0.109 \\
Model 3 & Two factor model & 6.706 & 0.734 & 0.704 & 0.729 \\
Model 4 & Single factor model & 8.128 & 0.67 & 0.644 & 0.679 & 0.149 \\
\hline
\end{tabular}

$(\beta=-0.190, P<0.01)$. Thus, $\mathrm{H} 6$ is verified. The contract governance and the relationship governance have a joint negative moderating effect on the relationship between intellectual property investment risk and asymmetric R\&D alliance stability $(\beta=-0.170, P<0.05)$. The moderating effect is shown in Figure 2. That is, the joint use of contract governance and relationship governance can effectively suppress the negative impact of intellectual property investment risk on the stability of asymmetric $R \& D$ alliance, and the double high-strength governance mechanism has the strongest moderating effect. Thus, H7 is verified. The contract governance and the relationship governance have a joint negative moderating effect on the relationship between the intellectual property loss risk and asymmetric $\mathrm{R} \& \mathrm{D}$ alliance stability $(\beta=-0.190, P<0.05)$. The moderating effect is shown in Figure 3 . That is, the combined use of contract governance and 
TABLE 3: Correlation between variables $(N=260)$.

\begin{tabular}{lcccccc}
\hline & AVE & Std & CG & RG & IS & LS \\
\hline CG & 4.907 & 1.274 & 0.838 & & & \\
RG & 5.008 & 1.132 & $0.607^{* *}$ & 0.763 & & \\
IS & 3.423 & 1.313 & $-0.234^{* *}$ & $-0.149 *$ & 0.788 & 0.740 \\
LS & 3.891 & 1.289 & $-0.184 *$ & $-0.085^{* *}$ & $0.604^{* *}$ & $-0.316^{* *}$ \\
AS & 4.457 & 1.082 & $0.508^{* *}$ & $0.417^{* *}$ & $-0.287^{* *}$ & 0.802 \\
\hline
\end{tabular}

${ }^{*} P<0.05,{ }^{* *} P<0.01$.

TABle 4: Hypothesis test results.

\begin{tabular}{|c|c|c|c|c|c|c|c|c|c|}
\hline & \multicolumn{9}{|c|}{ Asymmetric R\&D alliance stability } \\
\hline & M1 & M2 & M3 & M4 & M5 & M6 & M7 & M8 & M9 \\
\hline \multicolumn{10}{|c|}{ Control variable } \\
\hline Enterprise years & -0.091 & -0.093 & -0.052 & -0.051 & -0.047 & -0.106 & -0.061 & -0.066 & -0.064 \\
\hline Enterprise size & $0.191^{* *}$ & $0.200^{* *}$ & 0.087 & 0.094 & 0.081 & $0.169^{* *}$ & 0.064 & 0.059 & 0.059 \\
\hline \multicolumn{10}{|c|}{ Independent variable } \\
\hline IS & & $-0.317^{* *}$ & $-0.197^{* *}$ & $-0.201^{* *}$ & $-0.144 *$ & & & & \\
\hline LS & & & & & & $-0.330^{* *}$ & $-0.244^{* *}$ & $-0.248^{* *}$ & $-.236^{* *}$ \\
\hline \multicolumn{10}{|c|}{ Moderator } \\
\hline CG & & & $0.151 *$ & $0.166 *$ & $0.137 *$ & & $0.156 *$ & $0.175^{* *}$ & $0.176^{* *}$ \\
\hline RG & & & $0.374^{* *}$ & $0.379^{* *}$ & $0.411^{* *}$ & & $0.376^{* *}$ & $0.386^{* *}$ & $0.389^{* *}$ \\
\hline \multicolumn{10}{|c|}{ Two-dimension interaction } \\
\hline $\mathrm{IS} \times \mathrm{CG}$ & & & & $-0.230^{* *}$ & $-0.170 *$ & & & & \\
\hline $\mathrm{IS} \times \mathrm{RG}$ & & & & 0.003 & 0.057 & & & & \\
\hline $\mathrm{LS} \times \mathrm{CG}$ & & & & & & & & 0.135 & 0.128 \\
\hline $\mathrm{LS} \times \mathrm{RG}$ & & & & & & & & $-0.190^{* *}$ & $-0.210^{* *}$ \\
\hline $\mathrm{CG} \times \mathrm{RG}$ & & & & 0.047 & -0.057 & & & 0.015 & 0.002 \\
\hline \multicolumn{10}{|c|}{ Three-dimension interaction } \\
\hline $\mathrm{IS} \times \mathrm{CG} \times \mathrm{RG}$ & & & & & $-0.170 *$ & & & & \\
\hline $\mathrm{LS} \times \mathrm{CG} \times \mathrm{RG}$ & & & & & & & & & $-0.190 *$ \\
\hline $\mathbf{R}^{2}$ & 0.041 & 0.141 & 0.345 & 0.354 & 0.362 & 0.182 & 0.392 & .403 & 0.419 \\
\hline $\mathbf{F}$ & 5.548 & $14.166^{* *}$ & $26.804^{* *}$ & $18.842^{* *}$ & $15.663^{* *}$ & $14.166^{* *}$ & $28.404^{* *}$ & $20.482^{* *}$ & $18.663^{* *}$ \\
\hline$\Delta \mathbf{R}^{2}$ & 0.041 & 0.100 & 0.204 & 0.009 & 0.008 & 0.105 & 0.210 & 0.011 & 0.016 \\
\hline
\end{tabular}

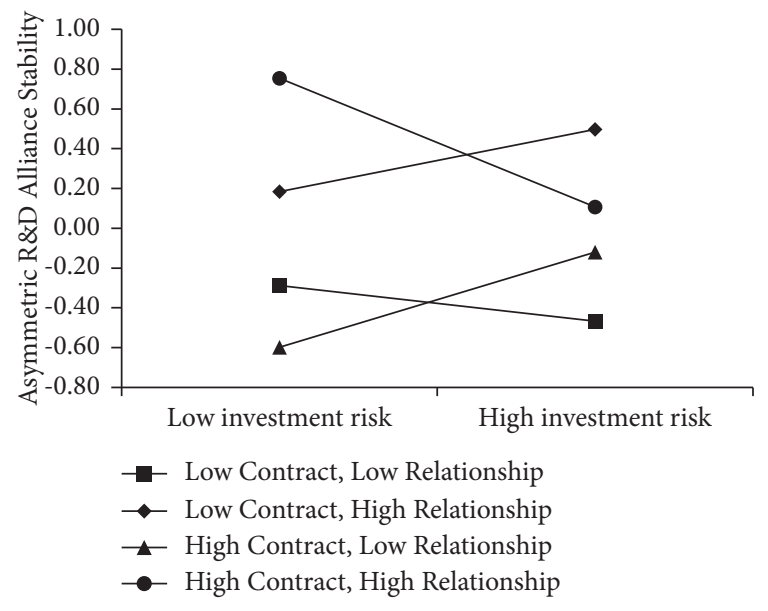

FIGURE 2: Joint moderating effect of CG and RG on the relationship between IS and AS.

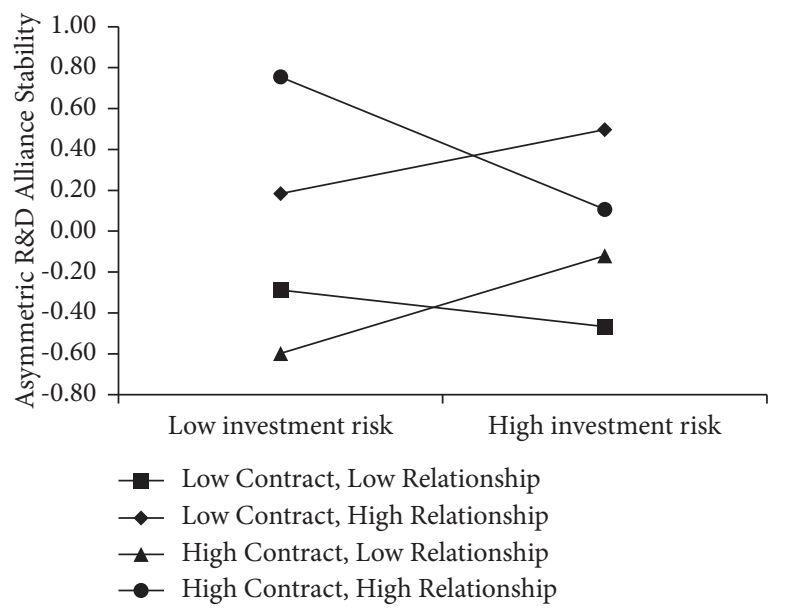

FIGURE 3: Joint moderating effect of CG and RG on the relationship between LS and AS. 
relationship governance can effectively suppress the negative impact of the intellectual property loss risk on the stability of asymmetric $\mathrm{R} \& \mathrm{D}$ alliance, and the double high-strength governance mechanism has the strongest moderating effect. Thus, H8 is verified.

\section{Conclusions and Implications}

6.1. Research Findings and Theoretical Contributions. This study comprehensively considers the individual and joint impact of the contract governance and relationship governance mechanism on the relationship between intellectual property risk and asymmetric R\&D alliance stability. Through model construction and data analysis, the following research conclusions are obtained. Firstly, intellectual property investment risk and intellectual property loss risk negatively impact asymmetric R\&D alliance stability. Secondly, contract governance negatively moderates the relationship between intellectual property investment risk and asymmetric R\&D alliance stability. The relationship governance negatively mediates the relationship between intellectual property loss risk and asymmetric R\&D alliance stability. Thirdly, the contract governance and the relationship governance have a joint negative moderating effect on the relationship between intellectual property investment risk and loss risk and asymmetric R\&D alliance stability. Specifically, the simultaneous adoption of high-level contract governance and high-level relationship governance can significantly moderate the negative impact of intellectual property investment and loss risk on asymmetric R\&D alliance stability. The main theoretical contributions of this research are as follows:

Firstly, this study analyzes the intellectual property risk in asymmetric alliance from the two-dimensional structure of intellectual property investment risk and intellectual property loss risk. By constructing a complete intellectual property risk model, the differential influence of intellectual property investment risk and intellectual property loss risk on the stability of asymmetric R\&D alliance is verified. Vulnerable enterprises face high intellectual property investment risk. They will conceal or reduce their investment in key knowledge and skills to avoid the high intellectual property investment risk, affect the effective resource stock of the alliance's knowledge pool, and reduce the success rate of cooperative $\mathrm{R} \& \mathrm{D}$, resulting in asymmetric $\mathrm{R} \& \mathrm{D}$ alliance break down. Intellectual property loss risk can cause alliance members to worry about the leakage of their core knowledge and technology, thereby overprotecting their knowledge in cooperative innovation, hindering the absorption and integration of knowledge among alliance members and triggering the instability of asymmetric R\&D alliance. Yang et al. (2018) pointed out that future research can analyze the alliance's stability from the perspective of intellectual property risk. This study carried out an empirical analysis from this perspective and supplemented the previous research results [51].

Secondly, this research systematically explored the governance mechanism of asymmetric $\mathrm{R} \& \mathrm{D}$ alliance and opened the theoretical black box of how the joint use of contract and relationship governance mechanism affects the relationship between intellectual property risk and the stability of asymmetric R\&D alliance. There are significant differences in the impact of different governance methods on intellectual property risks. The intellectual property investment risk mainly exists in the initial stage of cooperation, in which alliance members do not understand each other deeply, and the relationship governance cannot effectively play its positive role. Therefore, in the initial stage of cooperation, contract governance plays a major governance role. The contract provides clear written regulations on the amount of intellectual property that all members should invest, the share of cooperative $R \& D$ output and penalties for breach of contract. It restricts the speculative behavior of partners through the legal effect of the contract. Therefore, contract governance has a significant influence on intellectual property investment risk. This result is echoed by the conclusion of Rouyre and Fernandez (2019), which reveals the limited role of the relationship governance mechanism in knowledge risk governance [52]. The intellectual property loss risk mainly occurs in the middle phase of cooperation, in which the members have already established a certain connection. Therefore, at this stage, the relationship governance mainly plays a role. The relationship governance strengthens the trust and emotional exchanges among members, guides the members to care about the common interests of the R\&D alliance, reduces self-interested behaviors, and improves the consistency of cooperation goals, thus having a strong inhibitory effect on the intellectual property loss risk. However, contract governance has difficulty stipulating the cooperator's input in tacit knowledge. A contract that is too strict and rigid may make alliance members feel untrusted or threatened, destroying existing good cooperation relationship and thus forming obstacles to the transfer and sharing of knowledge within the asymmetric $\mathrm{R} \& \mathrm{D}$ alliance. As a result, contract governance has less impact on the intellectual property loss risk. This study's conclusion is consistent with the results of Schubert (2016). He believes that contract governance cannot provide effective protection for tacit knowledge but can easily damage the relationship between partners [19].

Thirdly, compared with previous studies that only discussed the main effect or the individual contingency effect alone, this study reveals the joint moderating effect of contract governance and relationship governance on the relationship between intellectual property risk and asymmetric R\&D alliance stability. At the same time, the adoption of a joint governance mechanism can significantly make up for the shortcomings of individual governance. It can substantially control the negative impact of intellectual property investment risk and intellectual property loss risk on the stability of asymmetric R\&D alliance. It provides a new idea for comprehensively explaining the influence mechanism of intellectual property risk on asymmetric $\mathrm{R} \& \mathrm{D}$ alliance stability. This finding is consistent with the research results of Gao (2017), who pointed out that the joint application of contract governance and relationship governance can effectively affect opportunistic behaviors between enterprises, but the inhibitory effect varies depending on the combination form of the two. 
High contract governance and high relationship governance have the strongest inhibitory effect [53].

6.2. Practical Enlightenment. Firstly, intellectual property investment risk and intellectual property loss risk will seriously undermine the stability of asymmetric $\mathrm{R} \& \mathrm{D}$ alliance. Identifying potential intellectual property risks in the alliance and constructing different forms of alliance governance mechanisms are needed to ensure the performance of R\&D alliance. From the perspective of intellectual property investment risk, even if the enterprises in the $R \& D$ alliance promise to invest in the information and knowledge they have, they may violate their promise. Therefore, increasing the rules consciousness of the alliance members and using detailed contract are needed to stipulate the scope of cooperation, the sharing of cooperation benefits, and the penalty for breaching a contract to curb the opportunistic behavior of alliance members and reduce the intellectual property investment risk. From the perspective of intellectual property loss risk, a culture of mutual trust should be cultivated among alliance members by setting common goals, strengthening the binding force of corporate reputation, coordinating the relationship structure between enterprises, and forming a culture of cooperation and sharing. Social relations control is used to restrain the opportunistic behavior of alliance R\&D cooperative members, thereby reducing intellectual property loss risk.

Secondly, to improve asymmetric R\&D alliance stability, two governance mechanisms, contractual and relational contracts, need to be jointly used. In the asymmetric R\&D alliance, the main risks faced by different stages are different, and the contractual contract governance and the relational contract governance have their corresponding defects. The double high-strength governance mechanism that pays equal attention to both emphasizes the role of relational governance in the $\mathrm{R} \& \mathrm{D}$ alliance for intellectual property risk avoidance and trust enhancement. It highlights the role of contract governance in restraining opportunistic behavior and ensuring the performance of cooperative innovation, effectively reducing the risk of intellectual property rights in R\&D cooperation and improving the stability of asymmetric $\mathrm{R} \& \mathrm{D}$ alliance.

6.3. Research Limitations. Although SMEs can obtain complementary innovation resources by participating in asymmetric R\&D alliance, they also face huge intellectual property risks and seriously threaten the stability of asymmetric $\mathrm{R} \& \mathrm{D}$ alliance. This study explores asymmetric R\&D alliance stability from the perspective of intellectual property risk. It investigates governance mechanisms that effectively suppress intellectual property risks and promote asymmetric R\&D alliance stability from the alliance level. Some important conclusions have been drawn through empirical research. However, this study also has limitations.

Firstly, although this study analyzes the factors affecting the stability of asymmetric $\mathrm{R} \& \mathrm{D}$ alliance from the perspective of intellectual property risk, for SMEs in a disadvantaged position, the knowledge sharing environment within the alliance and the economic and technological development environment outside the alliance are dynamic and complex. Therefore, enterprises' position in the alliance and their willingness to cooperate will change with their development and the alliance's. However, this study does not carry out a more in-depth dynamic analysis. Secondly, this study has limitations in the empirical analysis. For example, in terms of research samples, this study only investigates enterprises in asymmetric R\&D alliance in three provinces of China. For the study on the theme of $R \& D$ alliance, certain constraints are found in the scope of region and industry.

In the field of collaborative innovation, further research on the stability of asymmetric R\&D alliance can be carried out from the following aspects: (1) further studying on the impact of environmental dynamics on the stability of asymmetric R\&D alliance, (2) analyzing the mechanism and specific path of the impact of intellectual property risk on the stability of asymmetric R\&D alliance to provide valuable countermeasures and suggestions, and (3) enriching research samples. The coverage of research samples in regions, industries, and other aspects should also be continuously expanded to improve the accuracy and universality of research conclusions.

\section{Data Availability}

The data and models used during the study are available from the corresponding author by request.

\section{Conflicts of Interest}

The authors declare that there are no conflicts of interest regarding the publication of this paper.

\section{Authors' Contributions}

Zhuopin Guo and Jie Zhen conceptualized the study. Yiying $\mathrm{Qu}$ performed data analysis. Zhuopin Guo and Jie Zhen wrote the original draft. All the authors have read and agreed to the published version of the manuscript.

\section{Acknowledgments}

This research was funded by the National Social Science Found of China, grant no. 17BGL099; the Humanities and Social Sciences Foundation of the Ministry of Education of China, grant no. 19C10276025; and the science research program of the East China University of Political Science and Law.

\section{References}

[1] D. Fang and J. Wang, "Horizontal capacity sharing between asymmetric competitors," Omega-International Journal of Management Science and Engineering, vol. 97, pp. 102-109, 2020.

[2] Y. Feng, D. Teng, and B. Hao, "Joint actions with large partners and small-firm ambidexterity in asymmetric alliances: the mediating role of relational identification," International Small Business Journal: Researching Entrepreneurship, vol. 37, no. 7, pp. 689-712, 2019. 
[3] B. Hao and Y. Feng, "Leveraging learning forces in asymmetric alliances: small firms' perceived power imbalance in driving exploration and exploitation," Technovation, vol. 78, pp. 27-39, 2018.

[4] F. B. Korbi and M. Chouki, "Knowledge transfer in international asymmetric alliances: the key role of translation, artifacts, and proximity," Journal of Knowledge Management, vol. 21, no. 5, pp. 1272-1291, 2017.

[5] R. Falvey and K. T. Teerasuwannajak, "Competitive and harmonized $\mathrm{R} \& \mathrm{D}$ policies for international $\mathrm{R} \& \mathrm{D}$ alliances involving asymmetric firms," Review of International Economics, vol. 24, no. 2, pp. 302-329, 2016.

[6] Y. Luo, "From gain-sharing to gain-generation: the quest for distributive justice in international joint ventures," Journal of International Management, vol. 15, no. 4, pp. 343-356, 2009.

[7] D. Faems, B. Van Looy, M. Janssens, and P. W. L. Vlaar, "The process of value realization in asymmetric new venture development alliances: governing the transition from exploration to exploitation," Journal of Engineering and Technology Management, vol. 29, no. 4, pp. 508-527, 2012.

[8] K. Kalaignanam, V. Shankar, and R. Varadarajan, "Asymmetric new product development alliances: win-win or winlose partnerships?" Management Science, vol. 53, no. 3, pp. 357-374, 2007.

[9] B. Yu, H. Xu, and F. Dong, "Vertical vs. Horizontal: how strategic alliance type influence firm performance?" Sustainability, vol. 11, no. 23, p. 6594, 2019.

[10] R. Katila, J. D. Rosenberger, and K. M. Eisenhardt, "Swimming with sharks: technology ventures, defense mechanisms and corporate relationships," Administrative Science Quarterly, vol. 53, no. 2, pp. 295-332, 2008.

[11] Z. Cao and F. Lumineau, "Revisiting the interplay between contractual and relational governance: a qualitative and metaanalytic investigation," Journal of Operations Management, vol. 33-34, no. 1, pp. 15-42, 2015.

[12] S. V. Devarakonda and J. J. Reuer, "Knowledge sharing and safeguarding in R\&D collaborations: the role of steering committees in biotechnology alliances," Strategic Management Journal, vol. 39, no. 7, pp. 1912-1934, 2018.

[13] O. Schilke and F. Lumineau, "The double-edged effect of contracts on alliance performance," Journal of Management, vol. 44, no. 7, pp. 2827-2858, 2018.

[14] X. Jiang, F. Jiang, X. Cai, and H. Liu, "How does trust affect alliance performance? The mediating role of resource sharing," Industrial Marketing Management, vol. 45, pp. 128-138, 2015.

[15] F. Galati and B. Bigliardi, "Redesigning the model of the initiation and evolution of inter-firm knowledge transfer in $\mathrm{R} \& \mathrm{D}$ relationships," Journal of Knowledge Management, vol. 23, no. 10, pp. 2039-2066, 2019.

[16] G. Hamel and C. K. Prahalad, "Competing for the future," Harvard Business Review, vol. 72, pp. 122-128, 1994.

[17] B. Wernerfelt, "The resource-based view of the firm: ten years after," Strategic Management Journal, vol. 16, no. 3, pp. 171-174, 1995.

[18] H. Chen and T.-J. Chen, "Asymmetric strategic alliances," Journal of Business Research, vol. 55, no. 12, pp. 1007-1013, 2002.

[19] T. Schubert, "Infringement of intellectual property in innovation partnerships," $R$ \& $D$ Management, vol. 46, no. S2, pp. 596-611, 2016.

[20] K. Y. Zhang and R. H. Huang, "Analysis of intellectual property risk caused by partner's opportunistic behavior," Studies in Science of Science, vol. 25, pp. 740-744, 2007.
[21] C. A. Fulmer and M. J. Gelfand, "At what level (and in whom) we trust," Journal of Management, vol. 38, no. 4, pp. 1167-1230, 2012.

[22] P. Ritala, H. Olander, S. Michailova, and K. Husted, "Knowledge sharing, knowledge leaking and relative innovation performance: an empirical study," Technovation, vol. 35, pp. 22-31, 2015.

[23] S. Ren, L. Wang, W. Yang, and F. Wei, "The effect of external network competence and intrafirm networks on a firm's innovation performance: the moderating influence of relational governance," Innovation, vol. 15, no. 1, pp. 17-34, 2013.

[24] R. Manzini and V. Lazzarotti, "Intellectual property protection mechanisms in collaborative new product development," $R$ \& D Management, vol. 46, no. S2, pp. 579-595, 2016.

[25] T. Veer, A. Lorenz, and K. Blind, "How open is too open? The mitigating role of appropriation mechanisms in R\&D cooperation settings," $R$ \& $D$ Management, vol. 46, no. S3, pp. 1113-1128, 2016.

[26] Y. Liu, P. Deng, J. Wei, Y. Ying, and M. Tian, "International R\&D alliances and innovation for emerging market multinationals: roles of environmental turbulence and knowledge transfer," Journal of Business \& Industrial Marketing, vol. 34, no. 6, pp. 1374-1387, 2019.

[27] Y. Su and Y.-Q. Yu, "Spatial agglomeration of new energy industries on the performance of regional pollution control through spatial econometric analysis," The Science of the Total Environment, vol. 704, Article ID 135261, 2020.

[28] R. F. Lusch and J. R. Brown, "Interdependency, contracting, and relational behavior in marketing channels," Journal of Marketing, vol. 60, no. 4, pp. 19-38, 1996.

[29] C.-M. J. Yu, T.-J. Liao, and Z.-D. Lin, "Formal governance mechanisms, relational governance mechanisms, and transaction-specific investments in supplier-manufacturer relationships," Industrial Marketing Management, vol. 35, no. 2, pp. 128-139, 2006.

[30] T. L. Huber, T. A. Fischer, J. Dibbern, and R. Hirschheim, “A process model of complementarity and substitution of contractual and relational governance in IS outsourcing," Journal of Management Information Systems, vol. 30, no. 3, pp. 81-114, 2014.

[31] H. Ness and S. A. Haugland, "The evolution of governance mechanisms and negotiation strategies in fixed-duration interfirm relationships," Journal of Business Research, vol. 58, pp. 1226-1239, 2003.

[32] M. Seitz and M. Watzinger, "Contract enforcement and R\&D investment," Research Policy, vol. 46, no. 1, pp. 182-195, 2017.

[33] T. Roxenhall and P. Ghauri, "Use of the written contract in long-lasting business relationships," Industrial Marketing Management, vol. 33, no. 3, pp. 261-268, 2004.

[34] B. Lawson, K. J. Petersen, P. D. Cousins, and R. B. Handfield, "Knowledge sharing in interorganizational product development teams: the effect of formal and informal socialization mechanisms," Journal of Product Innovation Management, vol. 26, no. 2, pp. 156-172, 2009.

[35] J. J. Reuer and A. Ariño, "Strategic alliance contracts: dimensions and determinants of contractual complexity," Strategic Management Journal, vol. 28, no. 3, pp. 313-330, 2007.

[36] J. J. Ebbers, "Networking behavior and contracting relationships among entrepreneurs in business incubators," Entrepreneurship: Theory and Practice, vol. 38, pp. 1159-1181, 2013.

[37] Y. Su, X. Jiang, and Z. Lin, "Simulation and relationship strength: characteristics of knowledge flows among subjects in 
a regional innovation system," Science Technology \& Society, Article ID 09717218211020476, 2021.

[38] R. B. Bouncken, T. Clauss, and V. Fredrich, "Product innovation through coopetition in alliances: singular or plural governance?" Industrial Marketing Management, vol. 53, pp. 77-90, 2016.

[39] D. Pittino and P. A. M. Mazzurana, "Alliance governance and performance in SMEs: matching relational and contractual governance with alliance goals," Entrepreneurship Research Journal, vol. 3, pp. 62-83, 2013.

[40] D. J. Schepker, W.-Y. Oh, A. Martynov, and L. Poppo, "The many futures of contracts," Journal of Management, vol. 40, no. 1, pp. 193-225, 2014.

[41] Y. Long, P. Li, and B. You, "Knowledge transfer, governance mechanisms in alliance and environmental uncertainty," Chinese Management Studies, vol. 8, no. 3, pp. 438-472, 2014.

[42] T. Mellewigt, A. Madhok, and A. Weibel, "Trust and formal contracts in interorganizational relationships - substitutesand complements," Managerial and Decision Economics, vol. 28, no. 8, pp. 833-847, 2007.

[43] F. Lumineau and J. E. Henderson, "The influence of relational experience and contractual governance on the negotiation strategy in buyer-supplier disputes," Journal of Operations Management, vol. 30, no. 5, pp. 382-395, 2012.

[44] J. J. Li, L. Poppo, and K. Z. Zhou, "Relational mechanisms, formal contracts, and local knowledge acquisition by international subsidiaries," Strategic Management Journal, vol. 31, pp. 349-370, 2009.

[45] B. A. Heiman and J. A. Nickerson, "Empirical evidence regarding the tension between knowledge sharing and knowledge expropriation in collaborations," Managerial and Decision Economics, vol. 25, no. 67, pp. 401-420, 2004.

[46] S. Nambisan and M. Sawhney, "Orchestration processes in network-centric innovation: evidence from the field," Academy of Management Perspectives, vol. 25, no. 3, pp. 40-57, 2011.

[47] M. E. Marcus, "Embedded ties and the acquisition of competitive capabilities," Strategic Management Journal, vol. 26, pp. 1033-1055, 2005.

[48] X. Jiang, Y. Li, and S. Gao, "The stability of strategic alliances: characteristics, factors and stages," Journal of International Management, vol. 14, no. 2, pp. 173-189, 2008.

[49] J. F. Hair, W. C. Black, B. J. Babin, R. E. Anderson, and R. L. Tatham, Multivariate Data Analysis, Prentice-Hall, Hoboken, NJ, USA, 1998.

[50] L. S. Aiken and S. G. West, Multiple Regression: Testing and Interpreting Interactions, Sage, Newcastle upon Tyne, UK, 1991.

[51] Z. L. Yang, H. Zhao, and X. Y. Liu, "Technologic strategic alliances' driving, cooperation optimizing and stability of strategic alliance," Studies in Science of Science, vol. 36, no. 4, pp. 691-700, 2018.

[52] A. Rouyre and A.-S. Fernandez, "Managing knowledge sharing-protecting tensions in coupled innovation projects among several competitors," California Management Review, vol. 62, no. 1, pp. 95-120, 2019.

[53] M. L. Gao, "Research on the reciprocity of opportunism behavior and governance mechanisms in the collaborative innovation," Studies in Science of Science, vol. 35, no. 9, pp. 1422-1433, 2017. 